\title{
HDAC Inhibitor CHR-2845
}

National Cancer Institute

\section{Source}

National Cancer Institute. HDAC Inhibitor CHR-2845. NCI Thesaurus. Code C82690.

\begin{abstract}
A hydroxamic acid-derived histone deacetylase (HDAC) inhibitor with potential antineoplastic activity. CHR-2845 inhibits HDAC leading to an accumulation of highly acetylated histones, which may result in chromatin remodeling, inhibition of tumor oncogene transcription, inhibition of tumor cell division, and the induction of tumor cell apoptosis. HDAC, an enzyme upregulated in many tumor types, deacetylates chromatin histone proteins; this agent may specifically target HDACs in cells of the monocytemacrophage lineage.
\end{abstract}

